\title{
Pressure Effects on Structural Relaxation of La-Al-(Cu, Ni) Bulk Metallic Glass
}

\author{
Wang Fenghua ${ }^{1}, \quad$ Lin Jianguo ${ }^{1,2}, \quad$ Zhai Jiayou ${ }^{1}, \quad$ Luo Lian ${ }^{1}, \quad$ Ren Guozhong ${ }^{1}$ \\ ${ }^{1}$ Key Laboratory of Low Dimensional Materials \& Application Technology (Ministry of Education), Xiangtan University, Xiangtan 411105, P. R. \\ China; ${ }^{2}$ Deakin University, Geelong 3217, Victoria, Australia
}

\begin{abstract}
In this study, $\mathrm{La}_{62.0} \mathrm{Al}_{15.7}\left(\mathrm{Cu}_{0.5} \mathrm{Ni}_{0.5}\right)_{22.3}$ bulk metallic glasses (BMGs) were prepared by copper mold casting method, and the effects of the pressure treatment up to $5.0 \mathrm{GPa}$ at room temperature on structural relaxation were investigated by X-ray diffraction (XRD) and differential scanning calorimeter (DSC). The results showed that structural relaxation occurred with changes of the glass transition temperature $\left(T_{\mathrm{g}}\right)$ and the onset of primary crystallization $\left(T_{\mathrm{x} 1}\right)$. Both increased with increasing of applied pressure up to $4.0 \mathrm{GPa}$ beyond which they decreased. The enthalpy changed at the glass transition temperature regime showed that the reduction of the free volume caused by the HP treatment can be interpreted by the activation volumes of the flow defects. Furthermore, the HP treatment also influenced the crystallization sequence of the BMG.
\end{abstract}

Key words: bulk metallic glass; high pressure; structural relaxation

Metallic glasses are receiving much attention due to their excellent mechanical properties, such as high strength, high fracture toughness and high elastic limits. These properties arise from their disordered atomic structures ${ }^{[1-3]}$. As a non-equilibrium material, metallic glasses undergo structural changes from the amorphous state to the metastable structurally relaxed state and finally to the crystalline state while moderately heated. Therefore, by thermal annealing, bulk metallic glasses (BMG) could be crystallized to bulk nanostructural materials ${ }^{[4-5]}$. Recently, it is found that high pressure (HP) is a powerful tool for controlling nucleation and growth by changing atomic spacing, chemical bonding and Gibbs free energy in metallic glasses ${ }^{[6-7]}$. Thus, the crystallization behaviors of BMGs under high pressure have been extensively studied in recent years, aiming to gain insight into the mechanism of the nucleation and growth processes in BMGs. The crystallization in BMG is complicated by the structural relaxation and the possible phase separation before the onset of primary crystallization and diffusion fluxes in the supercooled liquid state ${ }^{[8]}$. Therefore, a systematic study of the effects of pressure on the structural relaxation of BMGs is helpful to understand the crystallization process. Because the mechanical behavior is strongly dependent on the microstructure of materials, significant improvements are possible through relaxation and removal of free volume by pressure treatment, particularly of the plasticity of the $\mathrm{BMGs}^{[9-10]}$. La-bluk metallic glasses have a very high glass forming ability and low glass transition temperature. In the present work, a La-based BMG was annealed under pressures up to $5.0 \mathrm{GPa}$ at room temperature. The effects of the high pressure treatment on the glass transition temperature, the onset temperature of the crystallization and reduction of free volume of BMG were investigated.

\section{Experimental}

A master alloy with the nomination composition of $\mathrm{La}_{62.0} \mathrm{Al}_{15.7}\left(\mathrm{Cu}_{0.5} \mathrm{Ni}_{0.5}\right)_{22.3}$ was prepared by melting a mixture of pure elements in Ti-gettered arc furnace. The metallic glass rod was obtained by injection of the liquid alloy into a copper mould with a diameter of $3 \mathrm{~mm}$. The samples for high pressure treatment were cut from the amorphous rod into the discs of $2 \mathrm{~mm}$ thickness and $3 \mathrm{~mm}$ diameter.

High pressure experiments were carried out at room tem-

Received date: June 25, 2008

Foundation item: Project supported by the Hunan Science Foundation Grant (05JJ30110)

Biography: Wang Fenghua, Master, Faculty of Material \& Photoelectronic Physics, Xiangtan University, Xiangtan 411105, P. R. China, Tel: 0086-732-8292195, E-mail: f_h_wang@126.com 
perature on a cube-type multi-anvil press device. The pyrophyllite was used for the outside layer of pressure transmitting media, and the samples were embedded into sodium chloride $(\mathrm{NaCl})$ and boron nitride $(\mathrm{BN})$. The powdered sodium chloride and boron nitride could satisfy our experimental need because of its high chemical stability and excellent pressure transmitting behavior. The HP process was carried out under the selected pressures of 3.0, 3.5, 4.0, 4.5 and 5.0 GPa for a holding time of $60 \mathrm{~min}$.

The structures of the as-cast and HP treated samples were examined by X-ray diffraction (XRD) with monochromatic $\mathrm{Cu} \mathrm{K} \alpha$ radiation. Thermal analysis was performed with a TA Instruments Q10 differential scanning calorimeter (DSC) with an accuracy of $\pm 1 \mathrm{~K}$ at a heating rate of $20 \mathrm{~K} / \mathrm{min}$ in nitrogen atmosphere.

\section{Results and Discussion}

Fig. 1 shows the XRD patterns of $\mathrm{La}_{62.0} \mathrm{Al}_{15.7}\left(\mathrm{Cu}_{0.5} \mathrm{Ni}_{0.5}\right)_{22.3}$ BMG in the as-cast state and after HP treatment for $60 \mathrm{~min}$ at room temperature under 3.0, 3.5, 4.0, 4.5 and 5.0 GPa. It can be seen that no obvious crystallization occurred in all the samples with HP pretreatments. Comparing these XRD patterns, one can see that the diffusion scattering peak of the HP treated samples are lower than that of the as-cast sample, and the height of the scattering peaks exhibits a decreasing trend with the increase of applied pressures in the range of 3.0-4.0 $\mathrm{GPa}$. With the applied pressure further increasing to $5.0 \mathrm{GPa}$, the height of the diffusion scattering peak increases again, but it is still lower than that of the as-cast sample. The decrease of the height of the scattering peak is considered to be associated with the structural relaxation in $\mathrm{BMGs}^{[9]}$. Thus, the XRD analysis results revealed that thermal relaxation occurred in the samples after HP treatment.

Fig.2 presents DSC traces of the as-cast and HP treated samples under different pressures at the heating rate of 20.0 $\mathrm{K} / \mathrm{min}$. All the samples exhibit distinct glass transitions, followed by super-cooled liquid regions (SLR), and then the exothermic reaction corresponding to crystallization. The

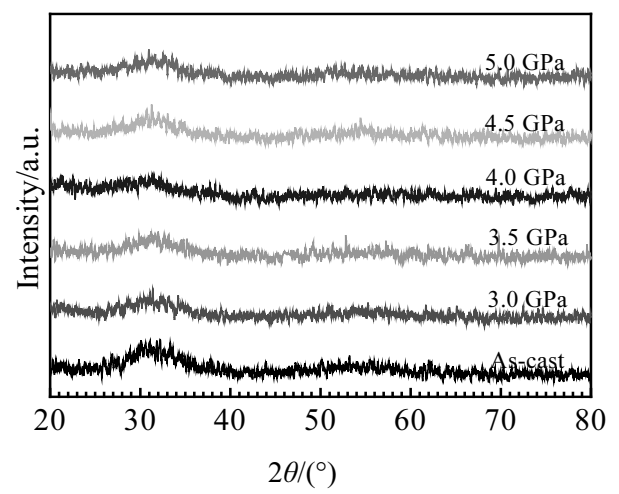

Fig.1 XRD patterns for the BMG in as-cast and HP pre-treated states at room temperature

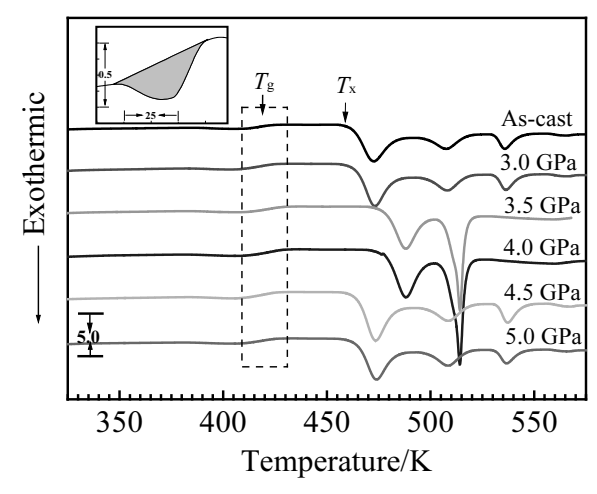

Fig.2 DSC curves for the as-cast and HP pre-treated samples at different high pressures (the heating rate is $20 \mathrm{~K} / \mathrm{min}$ ). The inset shows the plot of the enlarged view of the glass transition temperature regime

va ues of $T_{\mathrm{g}}, T_{\mathrm{x} 1}$ and $\operatorname{SLR}\left(\Delta T_{\mathrm{x}}=T_{\mathrm{x}}-T_{\mathrm{g}}\right)$ change in the HP pre-treated samples. It can be seen that the glass transition temperature $T_{\mathrm{g}}$ displays a nonmonotonic increasing function of pressure. First, the glass transition temperature $T_{\mathrm{g}}$ increases to a maximum with increasing of applied pressure from 0 to 4.0 GPa, and then decreases with the continuous increasing of applied pressure. The changes of $T_{x 1}$ and $\Delta T_{\mathrm{x}}$ with the pressure are similar to $T_{\mathrm{g}}$ (Fig. 3). It is interesting to be noted that the maxima of $T_{\mathrm{g}}, T_{\mathrm{x} 1}$ and $\Delta T_{\mathrm{x}}$ appeared in the sample HP treated at the pressure of $4.0 \mathrm{GPa}$, and the second crystallization peak of the sample became sharper but the third crystallization peak dsappeared.

The inset of Fig. 2 shows the plot of the enlarged view of the glass transition temperature regime. The enthalpy changes relating to the structural relaxation as a function of applied pressure are presented in Fig.4. It can be seen that the enthalpy change increases with the increase of the applied pressure up to $4.0 \mathrm{GPa}$, and then decrease with the applied pressure further increasing to $5.0 \mathrm{GPa}$. Van den Beukel and Sietsma ${ }^{[11]}$ analyzed the DSC thermograms of a Pd-based metallic glass and developed a model describing the functional form of the DSC curves based on the free volume theory in which a similar exothermic peak was observed. According to their model, in the super cooled liquid region, there is an equilibrium free-volume, $v_{\mathrm{fe}}$, at a given pressure, which is given by the equation as:

$$
v_{\mathrm{fe}}=A\left(P-P_{0}\right)
$$

where $P_{0}$ is the ideal glass pressure and $A$ is proportionality constant. An as-cast alloy contains an excess amount of the free volume $\left(v_{\mathrm{f}}\right)$ due to the non-equilibrium processing conditions D uring continuous heating in a DSC experiment, the free volume annihilates and approaches $v_{\mathrm{fe}}$. Thus, we have $v_{\mathrm{f}}$ $>v_{\mathrm{fe}}$. The reduction of the free volume gives rise to the heat release, $\Delta H$, when the glassy sample is heated during the DSC test, and the heat release relating to the structural relaxation is confirmed to be proportional to the reduction of the free vol- 


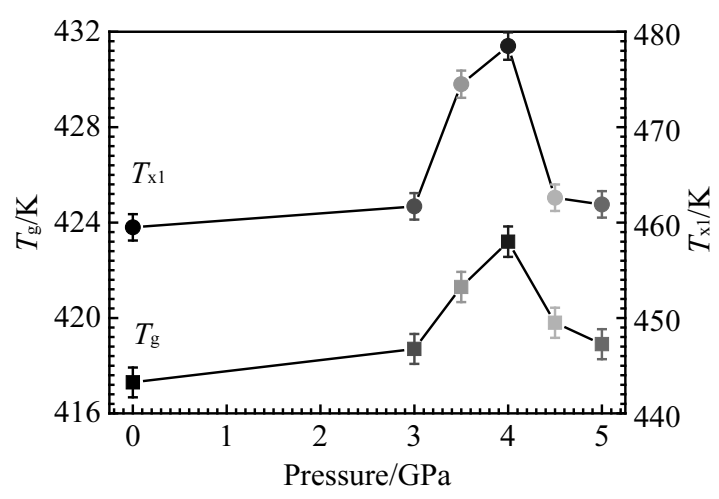

Fig.3 The glass transition temperature $\left(T_{\mathrm{g}}\right)$ and onset temperature $\left(T_{\mathrm{x} 1}\right)$ as a function of the applied pressure

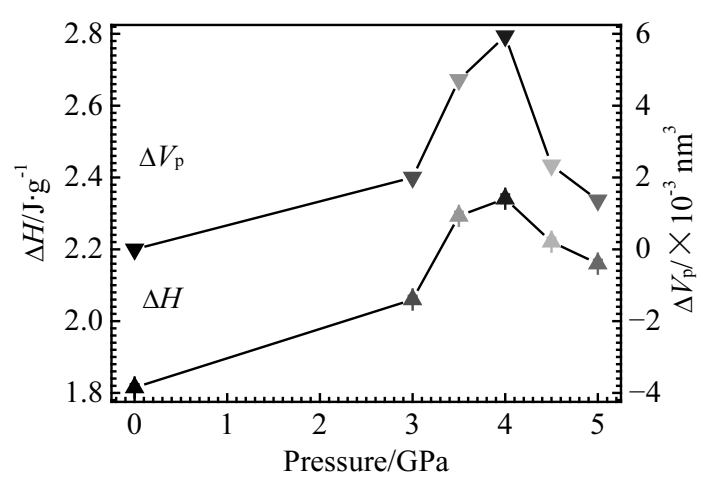

Fig.4 Variation of the enthalpy change at glass transition temperature regime and activation volume with the applied pressure

ume, i.e., $\Delta H \propto \Delta v_{\mathrm{f}}^{[12-13]}$. Therefore, the change of the heat release with the applied pressure in Fig.4 indicates that the structural relaxation occurred in the HP treated samples, and the reduction of free volume increased with the increase of the applied pressure up to $4.0 \mathrm{GPa}$, and then decreased with the applied pressure further increasing to $5.0 \mathrm{GPa}$.

Physically, the structural relaxation process involves the movement of atoms and the annihilation of the excess free volume, and high pressure promotes the collapse of the free volume and reconstruction of the atomic configuration in the glassy alloy ${ }^{[14]}$. In Ref.[15], K. Lu et al. used activation (formation and migration) volumes of the flow defect in terms of the free volume model to interpret the pressure dependence of the structural relaxation and $T_{\mathrm{g}}$ in terms of the free volume model. At different pressures of $P_{1}$ and $P_{2}$, glass transition occurs at $T_{\mathrm{g}-1}$ and $T_{\mathrm{g}-2}$, respectively. The activation volume caused by the hydrostatic pressure, $\Delta V_{\mathrm{p}}$, can be described as:

$$
\Delta V_{P}=B \cdot k \cdot\left[\frac{1}{T_{g-1}-T_{0}}-\frac{1}{T_{g-2}-T_{0}}\right] /\left[\frac{P_{2}}{T_{g-2}}-\frac{P_{1}}{T_{g-1}}\right]
$$

where $B$ is the fragility parameter and $T_{0}$ is the Vogel temperature. The values are usually determined by fitting to the viscosity $(\eta)$ of the liquids with temperature by equation as follows: $\eta=\eta_{0} \exp \left(B / T-T_{0}\right)$

The fragility parameter $\mathrm{B}$ and $T_{0}$ for the metallic glass $\mathrm{La}_{62} \mathrm{Al}_{14} \mathrm{Cu}_{24}$ similar to the current alloy can be found in Ref. [16], which are $2613 \mathrm{~K} / \mathrm{s}$ and $359 \mathrm{~K}$. Substituting the constants and variables in the equation (2) with the values of $B$ and $T_{0}$ and the data obtained in the present work, we can obtain the activation volume of the HP pretreated samples at the different pressures relative to the as-cast sample. The calculated activation volumes as a function of the applied pressures were also plotted in Fig.4. It is can be seen that the activation volume increases with the applied pressure up to $4.0 \mathrm{GPa}$, and then decrease with the pressure further increasing to $5.0 \mathrm{GPa}$. The change tendency is in a good agreement with that of the enthalpy change relating to the structure relaxation.

The effects of the pressure on the structure relaxation and the phase transition of BMGs lie in: (1) the high pressure promotes a short-range atomic rearrangement in metallic glass by the reduction of the free volume, which favors the homogeneous formation of crystal nuclei in BMG matrix; (2) the high pressure limits the long-distance atomic diffusion because of the increase of viscosity and the reduction of the free volume, which does not favor the growth of formed nucleus ${ }^{[17]}$. W.H. Wang et al. studied the effects of the applied pressure on the structure relaxation and phase transition close to and below the glass transition temperatures in $\mathrm{Zr}_{41.2} \mathrm{Ti}_{13.8} \mathrm{Cu}_{12.5^{-}}$ $\mathrm{Ni}_{10} \mathrm{Be}_{22.5}$ (Vit 1) $\mathrm{BMG}^{[9]}$. The nonmonotonic change of $T_{\mathrm{g}}$ with the applied pressure in Vit $1 \mathrm{BMG}$ annealed at $573 \mathrm{~K}$ at high pressure up to $5.0 \mathrm{GPa}$ was also found in their work. However, in their recent literature ${ }^{[10]}$, it was reported that, when the Vit 1 alloy was HP treated at ambient temperature, its Tg was independent on the applied pressure, but its crystallization peaks, including the first, the second and the third crystallization peak, moved to higher temperatures with the increase of the applied pressure. The change of the glass transition temperature with the applied pressure in the present work is similar to that of Vit $1 \mathrm{BMG}$ annealed at $573 \mathrm{~K}$. But it should be noted that, comparing with $T_{\mathrm{g}}$ of the as-cast alloy, the maximum change of $T_{\mathrm{g}}$ in the current alloy is $6 \mathrm{~K}$, which is much lower than that of Vit 1 (the maximum change value is $35 \mathrm{~K}$ ). So, to some extent, the applied pressure has little influence on the transition temperature of the present alloy treated at room temperature at the pressures up to 5.0 GPa. Our result is similar to that of Vit1 alloy treated under almost same conditions. The dependency of $T_{\mathrm{x} 1}$ on the applied pressure of the present alloy is some different from that of the Vit 1 HP treated at room temperature reported in Ref.[17], in which, $T_{\mathrm{x} 1}$ exhibited monotonic increase with the applied pressure. But our result reveals that $T_{\mathrm{x} 1}$ in the present alloy displays a nonmonotonic increasing function of the applied pressure, and the highest crystallization temperature occurred in the sample treated at $4.0 \mathrm{GPa}$. Furthermore, the DSC trace of this sample shows that the second crystallization peak became sharper but the third crystallization peak disappeared, 
which implies that high pressure treatment in the range of 3.5-4.0 GPa changed the crystallization sequence of the BMG. Now we still cannot give an explanation to this phenomenon. However, the crystallization of the present BMG is a multistage process, and the activation energy $\left(\Delta E_{x}\right)$ of crystallization of binary metallic glass was confirmed to be pressure dependent, and an appropriate pressure could lower the $\Delta E_{x}$ for crystallization $^{[18]}$. Thus, the effects of the pressure on the different crystallization stages are different, and the crystallization stages with relatively lower value of $\Delta E_{x}$ is pressure promoted $^{[19]}$. Furthermore, the activation energy of the nucleation and growth is closely related to the local atomic structural ${ }^{[20]}$. It appears to be these reasons we observed the pressure-dependent crystallization process in the HP treated samples.

\section{Conclusions}

1) All samples are in full amorphous state, and the HP pretreatment does not cause any significant crystallization of the alloy.

2) HP pretreatment will change the glass transition temperature $\left(T_{\mathrm{g}}\right)$ and onset temperature $\left(T_{\mathrm{x} 1}\right)$ of the BMG. Both $T_{\mathrm{g}}$ and $T_{\mathrm{x} 1}$ increase to a maximum with increasing of applied pressure from 0 to $4.0 \mathrm{GPa}$, and then decrease with the applied pressure further increasing to $5.0 \mathrm{GPa}$.

3) The effect can be interpreted by the activation (formation and migration) volumes of the flow defect model proposed by $\mathrm{K}$. Lu et al.

4) The HP pretreatment will affect the crystallization sequence of the BMG. The samples treated at the pressure in the range of 3.5-4.0 GPa exhibit two stages of the crystallization, while others have three stages of the crystallization.

\section{References}

1 Inoue A, Zhang T, Masumoto T. Materials Transaction JIM[J], 1991, 31: 425

$2 \mathrm{Wu}$ Xueqing(吴学庆), Ma Mo(马 蓦), Tan Chaogui(檀朝桂) et al. Rare Metal Materials and Engineering(稀有金属材料与工程) [J], 2007, 36(9): 1668

3 Wang W H. Progress Material Science[J], 2007, 52: 540

4 Yu Gengsheng(喻更生), Li Fu(李 伏), Wei Bingchen(魏炳忱) et al. Rare Metal Materials and Engineering(稀有金属材料与工 程)[J], 2005, 34(3): 371

5 Wang X F et al. Material Letters[J], 2007, 61: 1715

6 Pan M X et al. Physics Letter A[J], 2002, 303: 229

7 Li H Q et al. Journal of Alloys and Compounds[J], 2007, 428: 185

8 Xing P F et al. Journal of Applied Physics[J], 2002, 91: 4956

9 Pan M X et al. Applied Physics Letters[J], 2001, 78: 601

10 Yu P et al. Applied Physics Letters[J], 2007, 90: 051906

11 van den Beukel, Seitsma A. Acta Materialia[J], 1990, 38: 383

12 Murali P, Ramamurty U. Acta Materialia[J], 2005, 53: 1467

$13 \mathrm{Yu}$ G S et al. Materials Science and Engineering A[J], 2007, 460-461: 158

14 Wen P et al. Physcial Review B[J], 2004, 68: 092201

15 Jin H J et al. Acta Materialia[J], 2003, 51: 6219

16 Jiang Q K et al. Acta Materialia[J], 2007, 55: 4409

17 Jin H et al. Acta Materialia[J], 2005, 53: 3013

18 Shen Z Y et al. Physcial Review B[J], 1989, 89: 2714

19 Zhang H W, Zhou T J. Physics Letter A[J], 2006, 350: 297

20 Akihiko Hirata et al. Intermetallics[J], 2006, 14: 903

\title{
压力对La-Al- $(\mathrm{Cu}, \mathrm{Ni})$ 金属玻璃结构驰豫的影响
}

\author{
王锋华 ${ }^{1}$, 林建国 ${ }^{1,2}$, 翟甲友 ${ }^{1}$, 罗 联 $^{1}$, 任国仲 ${ }^{1}$ \\ (1. 湘潭大学 低维材料及其应用技术教育部重点实验室, 湖南 湘潭 411105) \\ (2. Deakin 大学, 维多利亚 3217 , 澳大利亚)
}

\begin{abstract}
摘 要: 采用铜模吸铸法制备出 $\mathrm{La}_{62.0} \mathrm{Al}_{15.7}\left(\mathrm{Cu}_{0.5} \mathrm{Ni}_{0.5}\right)_{22.3}$ 大块金属玻璃, 经高压处理后, 用 $\mathrm{X}$ 射线衍射仪( $\mathrm{XRD}$ )和示差扫描量热计(DSC) 对非晶的结构驰豫和晶化过程进行了研究。结果表明, 非晶玻璃转变温度和第一晶化温度随着压力的增加, 其先增加后减小, 极大值出 现在 $4.0 \mathrm{GPa}$ 的压力。这种现象归因于经过高压处理后玻璃转变温度区焓的变化, 而焓的变化由基体缺陷激活体积引起自由体积变化所 导致。此外, 高压处理还影响玻璃的结晶过程。
\end{abstract}

关键词: 大块金属玻璃; 高压; 结构驰豫

作者简介: 王锋华, 男, 1982 年生, 硕士, 湘潭大学材料与光电物理学院, 湖南 湘潭 411105, 电话: 0732-8292195, E-mail: f_h_wang@126.com 